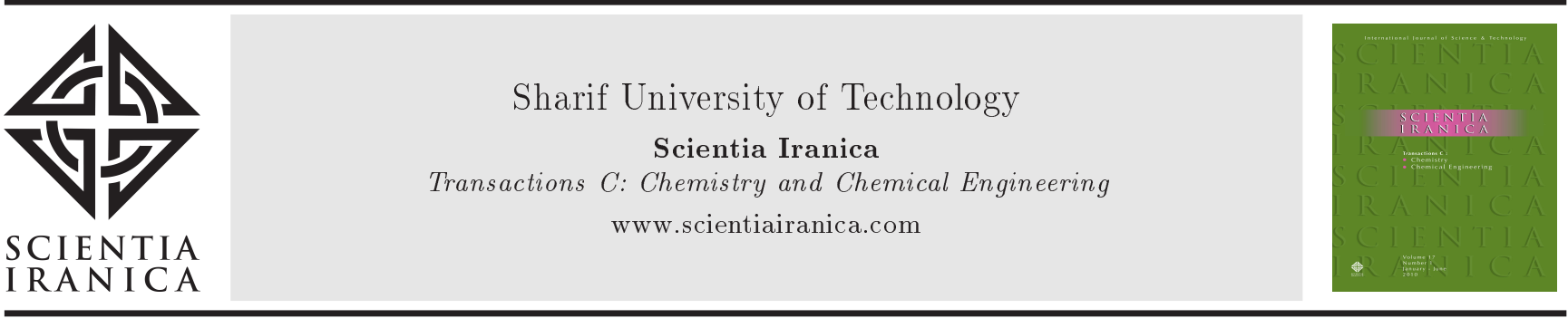

\title{
Optimization of ethylene oxychlorination fluidized-bed reactor using Differential Evolution (DE) method
}

\author{
M.H. Khademi ${ }^{a, *}$ and S. Angooraj Taghavi ${ }^{\mathrm{b}, c}$ \\ a. Department of Chemical Engineering, Faculty of Engineering, University of Isfahan, Isfahan, P.O. Box 81746-73441, Iran. \\ b. Chemical Engineering Department Fars Science and Research Branch, Islamic Azad University, Shiraz, Iran. \\ c. Department of Chemical Engineering, Shiraz Branch, Islamic Azad University, Shiraz, P.O. Box 71987-74731, Iran.
}

Received 22 December 2015; received in revised form 29 October 2016; accepted 7 January 2017

\section{KEYWORDS}

Ethylene dichloride; Ethylene oxychlorination; Fluidized-bed reactor; Optimization;

Differential evolution.

\begin{abstract}
The present work aims to employ Differential Evolution (DE) algorithm to optimize ethylene oxychlorination process to produce 1,2-dichloroethane in a fluidized bed reactor as a feedstock of PVC production. A steady-state reactor model, based on twophase theory of fluidization, was developed to investigate the effects of various parameters on $\mathrm{C}_{2} \mathrm{H}_{4}$ and $\mathrm{HCl}$ conversions. The model's results were compared favorably with the industrial data obtained from a pilot plant working in Italy. The feed temperature, pressure, $\mathrm{HCl}$ and $\mathrm{O}_{2}$ molar flow rates, and cooling medium temperature were selected as decision variables to minimize the objective function subject to the environmental constraints. The highest performance was found at $\mathrm{HCl} / \mathrm{C}_{2} \mathrm{H}_{4}$ and $\mathrm{O}_{2} / \mathrm{C}_{2} \mathrm{H}_{4}$ molar ratios of 2 and 0.55 , respectively; feed and cooling medium temperatures of 440 and $360 \mathrm{~K}$, respectively; pressure of $367.6 \mathrm{kPa}$. The results show a decrease of $20^{\circ} \mathrm{C}$ in the feed temperature, which leads to saving energy and reducing the size of the pre-heater.
\end{abstract}

(C) 2017 Sharif University of Technology. All rights reserved.

\section{Introduction}

Oxychlorination of ethylene is a chemical reaction in which oxygen and hydrogen chloride react with ethylene in vapor phase over a supported copper chloride catalyst to produce ethylene dichloride (EDC or 1,2dichloroethane) and water:

$$
\begin{aligned}
& \mathrm{C}_{2} \mathrm{H}_{4}+2 \mathrm{HCl}+1 / 2 \mathrm{O}_{2} \rightarrow \mathrm{C}_{2} \mathrm{H}_{4} \mathrm{Cl}_{2}+\mathrm{H}_{2} \mathrm{O}, \\
& \Delta H_{r}^{0}=-240 \mathrm{~kJ} / \mathrm{mol} .
\end{aligned}
$$

This reaction occurs at a temperature range of 473$573 \mathrm{~K}$ and a pressure of $0.4-0.6 \mathrm{MPa}[1,2]$. Since this reaction is highly exothermic, heat is removed by internal cooling coils submerged in the fluidized-bed.

\footnotetext{
*. Corresponding author. Tel.: +9831 37934075;

Fax: +983137934031

E-mail address: m.khademi@eng.ui.ac.ir (M.H. Khademi)
}

EDC is a major chemical intermediate which belongs to a group of chemicals with the highest annual production rate. EDC is the precursor of Vinyl Chloride Monomer (VCM), which is polymerized to polyvinyl chloride (PVC). PVC polymer is utilized commercially in a wide variety of useful vinyl plastic products and appears in both rigid and flexible (plasticized) forms. These products include plastic pipe, vinyl house siding, flooring and wall covering, window frames, wire insulation, vinyl seat covers, recording discs, and many others.

Only a few papers in the literature are concerned with mathematical modeling of ethylene oxychlorination fluidized-bed reactor. Al-Zahrani et al. [3] investigated the effects of different parameters on the behavior of ethylene oxychlorination for EDC production in a fluidized-bed reactor. Prasad et al. [4] estimated the rate parameters of ethylene oxychlorination reaction by developing an unsteady-state model in a fixed-bed 
reactor while taking into account the change in catalyst composition, variation of temperature profiles, and exit gas-phase conversions with time. A two-step ethylene oxychlorination process of oxidation and reduction reactions was carried out in the fluidized-bed reactor by Go et al. [5]. They studied the effects of superficial gas velocity and gas composition on the reactivity and fluidization stability using an experimental set-up. Keshavarz Moraveji et al. [6] modeled a fluidized bed reactor for 1,2-dichloroethane production from ethylene oxychlorination by computational fluid dynamics. The effect of catalyst amount was considered carefully. They showed that the enhancement of catalyst up to 6 $\mathrm{m}$ (height of the bed) increases the products efficiency, especially 1,2-dichloroethane. Recently, Montebelli et al. [7] have presented a development and validation of a new kinetic model for the ethylene oxychlorination reaction, relying on 9 chemical reactions to describe the evolution of 12 species (including 6 major byproducts). They also reported two mathematical models of oxychlorination fluidized-bed reactors, namely the simple two-phase and the axially dispersed plug-flow models, as well as their comparative validation against industrial data.

To the best of our knowledge, the mathematical modeling of ethylene oxychlorination reactor has been carried out by a few researchers in order to achieve two goals: investigating the effects of operational parameters on the reactor performance and estimating the reaction kinetic parameters. Furthermore, no study has been found about the optimization of the ethylene oxychlorination reactor. To improve the reactor performance, economic feasibility, and safety, it is required to operate the reactor under optimal conditions.

In this work, a steady-state distributed mathematical model is developed for ethylene oxychlorination to produce EDC in a fluidized-bed reactor. A sensitivity analysis is carried out to indicate numerically the effects of various key operating variables on the performance of the reactor. Finally, the purpose of this study is to optimize the ethylene oxychlorination fluidized-bed reactor using a Differential Evolution (DE) algorithm as an exceptionally simple evolution strategy. The feed temperature, pressure, $\mathrm{HCl}$ and $\mathrm{O}_{2}$ molar flow rates, and cooling medium temperature are considered as decision variables to minimize the defined objective function.

\section{Mathematical modeling}

The two-phase model, bubbling bed model proposed by Kunii and Levenspiel [8], which considers a fluidized bed as consisting of a bubble phase and a dense (or emulsion) phase, has been proven to be the most suitable model for incorporating recent findings in the hydrodynamics of fluidization. This model proposes a separate governing equation for each phase and mass interchange between them.

\subsection{Assumptions}

The following assumptions are incorporated in the development of the mathematical model:

i The bubble gas is devoid of solids and is in plug flow;

ii The extent of reaction in the bubble-cloud phase is negligible. This assumption is justified by the experimental evidence reported by Toor and Calderbank [9] for small-sized particles and high flow rates;

iii The dense phase is assumed to be perfectly mixed and uniform in temperature;

iv An average value of the bubble size, and hence, an average value of the inter-phase exchange parameter are used for the whole bed. The effective bubble size is taken as that which exists at $40 \%$ of the expanded bed height [10];

$\mathrm{v}$ The mass and heat transfer resistances between the particles and the dense-phase gas are negligible;

vi The ideal gas law applies to the gas phase in both phases;

vii The volumetric flow rate through the bubble phase is constant.

\subsection{Mass and energy balances}

The material balance of the $i$ th component and the energy balance equations are developed for the bubble and dense phases at steady state, allowing for a change in volumetric flow rate in the dense phase gas. These equations followed by boundary conditions and ideal gas law equations are summarized in Table 1. Rearranging Eqs. (2) and (3), integrating them by using boundary conditions, and then substituting them into Eqs. (4) and (5), respectively, as well as ideal gas law equations result in the following equations:

$$
\begin{gathered}
N_{i d}=x_{i f} N_{f} \frac{Q_{d f}}{Q_{f}}+\frac{P A_{b} u_{b}}{R}\left(\frac{x_{i f}}{T_{f}}-\frac{x_{i d}}{T_{d}}\right)\left(1-e^{-\alpha_{i} H}\right) \\
+V(1-\delta)(1-\varepsilon) \gamma_{i} r \\
\rho_{g} C_{p g} Q_{d f}\left(T_{f}-298\right)-\rho_{g} C_{p g} Q_{d}\left(T_{d}-298\right) \\
+u_{b} \rho_{g} C_{p g} A_{b}\left(T_{f}-T_{d}\right)\left(1-e^{-\beta H}\right) \\
+h_{w} A_{w}\left(T_{w}-T_{d}\right)+V(1-\delta)(1-\varepsilon) \\
\left(-\Delta H_{r}\right) r=0
\end{gathered}
$$

where $\alpha_{i}=\frac{\left(K_{b d}\right)_{i b}}{u_{b}}$ and $\beta=\frac{H_{b d}}{u_{b} \rho_{g} C_{p g}}$. 
Table 1. Mass and energy balance equations and boundary conditions for the bubble and dense phases as well as ideal gas law equations [11].

\begin{tabular}{|c|c|c|}
\hline Equation type & Equation & Equation no. \\
\hline $\begin{array}{l}\text { Mass and } \\
\text { energy balances } \\
\text { in bubble phase }\end{array}$ & $\frac{d N_{i b}}{d z}=A_{b}\left(K_{b d}\right)_{i b}\left(\frac{N_{i d}}{Q_{d}}-\frac{N_{i b}}{Q_{b}}\right)$ & $(2)$ \\
\hline & $u_{b} \rho_{g} C_{p g} \frac{d T_{b}}{d z}=\left(H_{b d}\right)_{b}\left(T_{d}-T_{b}\right)$ & $(3)$ \\
\hline $\begin{array}{l}\text { Mass and } \\
\text { energy balances }\end{array}$ & $\begin{array}{l}N_{i d}=N_{i d f}+\int_{0}^{H}\left(K_{b d}\right)_{i b} A_{b}\left(\frac{N_{i b}}{Q_{b}}-\frac{N_{i d}}{Q_{d}}\right) d z+V(1-\delta)(1-\varepsilon) \gamma_{i} r \\
\rho_{g} C_{p g} Q_{d f}\left(T_{f}-298\right)-\rho_{g} C_{p g} Q_{d}\left(T_{d}-298\right)+\int_{0}^{H}\left(H_{b d}\right)_{b} A_{b}\left(T_{b}-T_{d}\right) d z\end{array}$ & $(4)$ \\
\hline in dense phase & $+h_{w} A_{w}\left(T_{w}-T_{d}\right)+V(1-\delta)(1-\varepsilon)\left(-\Delta H_{r}\right) r=0$ & $(5)$ \\
\hline & $x_{i d} P Q_{d}=N_{i d} R T_{d}$ & $(6)$ \\
\hline Ideal gas law & $\begin{array}{l}x_{i f} P Q_{f}=N_{i f} R T_{f} \\
N_{i d f}=x_{i f} N_{f} \frac{Q_{d f}}{Q_{f}}\end{array}$ & $\begin{array}{l}(7) \\
(8)\end{array}$ \\
\hline Boundary condition & at $z=0, N_{i b}=N_{i b f} \quad T_{b}=T_{f}$ & \\
\hline
\end{tabular}

\subsection{Hydrodynamic and transport property correlations}

Table 2 shows the hydrodynamic and transport property correlations used in this study.

\subsection{Reaction kinetics}

Several mechanism and kinetic studies have been reported in the literature for ethylene oxychlorination [18-20]. In this paper, a rate equation of the Hougen-Watson type, reported by Carrubba and Spencer [18], is used. This reaction rate model was based on the surface reaction of ethylene and oxygen, on the $\mathrm{CuCl}_{2}-\mathrm{Al}_{2} \mathrm{O}_{3}$ based catalyst, to form an ethylene oxide intermediate as the rate-determining step. The reaction rate increases with increasing partial pressures of ethylene and oxygen, but it is independent of hydrogen chloride partial pressure. The reaction rate of EDC production has the following form:

$$
\begin{aligned}
r & =\frac{k_{r} P_{\mathrm{C}_{2} \mathrm{H}_{4}} P_{\mathrm{O}_{2}}^{1 / 2}}{\left[1+0.0017 P_{\mathrm{C}_{2} \mathrm{H}_{4}}+0.0355 P_{\mathrm{O}_{2}}^{1 / 2}+0.0165 P_{\mathrm{H}_{2} \mathrm{O}}\right]^{2}} \\
k_{r} & =6.83 \times 10^{-7} \exp (-E / R T),
\end{aligned}
$$

where $k_{r}$ is the reaction rate constant; $P_{\mathrm{C}_{2} \mathrm{H}_{4}}, P_{\mathrm{O}_{2}}$, and $P_{\mathrm{H}_{2} \mathrm{O}}$ are partial pressures of ethylene, oxygen, and water in millimeters of $\mathrm{Hg}$, respectively; $E$ is activation energy, $24.5 \mathrm{kcal} / \mathrm{mol}$; the rate is expressed as moles of EDC per liter-second.

\subsection{Numerical solution}

The solution of the mass balance equations is followed by the calculation of the heat balance equation.
Eq. (9) consists of five simultaneous nonlinear algebraic equations involving five unknowns (the number of moles of the five components), and is thus amenable to numerical solution techniques. The equations are solved by a combination of the Newton-Raphson and the bisection methods, as described by Wgialla et al. [11].

In the calculation, it is supposed that the heat of reaction and heat capacity are dependent on temperature. The thermal conductivity, heat capacity, and density of gas mixture are predicted through linear combination of properties of the individual component gases.

\section{Optimization}

\subsection{Differential Evolution (DE)}

Over the last few years, Differential Evolution (DE) algorithm has been proposed for dealing with optimization problems. DE algorithm is a stochastic optimization method minimizing an objective function that can model the problem's objectives while incorporating constraints. This algorithm mainly has three advantages: finding the true global minimum regardless of the initial parameter values, fast convergence, and using a few control parameters. Other important features of DE algorithm include: (a) being simple, fast and easy to use; (b) very easily adaptable to integrand discrete optimization; (c) being quite effective in non-linear constraint optimization including penalty functions; and (d) being useful for optimizing multi-modal search spaces.

Different strategies can be adopted in DE algorithm depending upon the type of problem to which $\mathrm{DE}$ 
Table 2. Hydrodynamic and transport property correlations.

\begin{tabular}{|c|c|c|}
\hline Parameter & Theoretical or empirical expressions & Ref. \\
\hline Bed voidage at minimum fluidization & $\begin{array}{l}\varepsilon_{m f}=0.586 \varphi_{s}^{-0.72} A r^{-0.029}\left(\frac{\rho_{g}}{\rho_{p}}\right)^{0.021} \\
A r=\rho_{g}\left(\rho_{p}-\rho_{g}\right) g \frac{d_{p}^{3}}{\mu^{2}}\end{array}$ & Broadhurst and Becker [12] \\
\hline Superficial velocity at minimum fluidization & $u_{m f}=\frac{\left(\varphi_{s} d_{p}\right)^{2} g\left(\rho_{p}-\rho_{g}\right)}{150 \mu} \frac{\varepsilon_{m f}^{3}}{1-\varepsilon_{m f}}$ & Kunii and Levenspiel [8] \\
\hline Bubble diameter & $\begin{array}{l}d_{B}=d_{B M}-\left(d_{B M}-d_{B} o\right) e^{-0.3 z / D} \\
d_{B M}=0.652\left[A\left(u_{f}-u_{m f}\right)\right]^{0.4} \\
d_{B o}=0.00376\left(u_{f}-u_{m f}\right)^{2}\end{array}$ & Mori and Wen [13] \\
\hline Bubble rising velocity & $u_{b}=u_{f}-u_{m f}+0.711\left(g d_{B}\right)^{0.5}$ & Davidson and Harrison [14] \\
\hline Fraction of bubble phase & $\delta=\frac{u_{f}-u_{m f}}{u_{b}}$ & Kunii and Levenspiel [8] \\
\hline Total feed volumetric flow rate & $Q_{f}=u_{f} A$ & Kunii and Levenspiel [8] \\
\hline Bubble-phase volumetric flow rate & $Q_{b}=\left(u_{f}-u_{m}\right) A$ & Kunii and Levenspiel [8] \\
\hline Dense-phase feed volumetric flow rate & $Q_{d f}=Q_{f}-Q_{b}$ & Kunii and Levenspiel [8] \\
\hline Expanded bed height & $H=\frac{H_{m f}}{1-\delta}$ & Kunii and Levenspiel [8] \\
\hline $\begin{array}{l}\text { Overall mass transfer } \\
\text { coefficient (bubble phase/dense } \\
\text { phase) based on bubble volume }\end{array}$ & $\begin{aligned} \frac{1}{\left(K_{b d}\right)_{i b}} & =\frac{1}{\left(K_{b c}\right)_{i b}}+\frac{1}{\left(K_{c d}\right)_{i b}} \\
\left(K_{b c}\right)_{i b} & =4.5\left(\frac{u_{m f}}{d_{B}}\right)+5.85\left(\frac{D_{i m}^{0.5} g^{0.25}}{d_{B}^{1.25}}\right) \\
\left(K_{c d}\right)_{i b} & =6.78\left(\frac{\varepsilon_{m f} D_{i m} u_{b}}{d_{B}^{3}}\right)^{0.5}\end{aligned}$ & Kunii and Levenspiel [8] \\
\hline $\begin{array}{l}\text { Overall heat transfer coefficient } \\
\text { (bubble phase/dense phase) based } \\
\text { on bubble volume }\end{array}$ & $\begin{array}{l}\frac{1}{\left(H_{b d}\right)_{b}}=\frac{1}{\left(H_{b c}\right)_{b}}+\frac{1}{\left(H_{c d}\right)_{b}} \\
\left(H_{b c}\right)_{b}=4.5\left(\frac{u_{m f} \rho_{g} C_{p g}}{d_{B}}\right)+5.85 \frac{\left(k_{g} \rho_{g} C_{p g}\right)^{0.5} g^{0.25}}{d_{B}^{1.25}} \\
\left(H_{c d}\right)_{b}=6.78\left(k_{g} \rho_{g} C_{p g}\right)^{0.5}\left(\frac{\varepsilon_{m f} u_{b}}{d_{B}^{3}}\right)^{0.5}\end{array}$ & Kunii and Levenspiel [8] \\
\hline $\begin{array}{l}\text { Heat transfer coefficient (bed-vertical tubes) } \\
\text { Binary diffusivity }\end{array}$ & $\begin{array}{l}h_{w}=0.88 \frac{k_{g}}{d_{p}} A r^{0.213} \\
D_{i j}=\frac{10^{-3} T^{1.75}\left(1 / M_{i}+1 / M_{j}\right)^{0.5}}{P\left(V_{i}^{0.33}+V^{0.33}\right)^{2}}\end{array}$ & Renz et al. [15] \\
\hline Diffusivity of component $i$ in gas mixture & $D_{i m}=\frac{1-x_{i}}{\sum_{\substack{j=1 \\
j \neq 1}}^{n} \frac{x_{i}}{D_{i j}}}$ & Reid et al. [17] \\
\hline
\end{tabular}

is applied. The strategies can vary based on the vector to be perturbed, number of difference vectors considered for perturbation, and finally the type of crossover used. Ten different working strategies, proposed by Price and Storn [21], are as follows:

1. DE/best/1/exp;

2. DE/rand/1/exp;

3. DE/rand-to-best/1/exp;

4. DE/best/2/exp;

5. DE/rand/2/exp;

6. DE/best/1/bin;

7. $\mathrm{DE} / \mathrm{rand} / 1 / \mathrm{bin}$;

8. DE/rand-to-best/1/bin;

9. DE/best/2/bin;
10. $\mathrm{DE} / \mathrm{rand} / 2 / \mathrm{bin}$.

The general convention used above is $\mathrm{DE} / x / y / z$, in which DE stands for differential evolution, $x$ represents a string denoting the vector to be perturbed, $y$ is the number of difference vectors considered for perturbation of $x$, and $z$ stands for the type of crossover being used (exp: exponential; bin: binomial).

Choosing population size (NP), scaling factor $(\mathrm{F})$, and crossover constant (CR) depends on the specific problem applied, which is often difficult. But, some general guidelines are available. Normally, NP should be about 5 -10 times the number of parameters in a vector. As for $F$, it lies in the range 0.4-1.0. Initially, $F=0.5$ can be tried, then $F$ and/or NP are increased if the population converges prematurely. A good first choice for $\mathrm{CR}$ is 0.1 , but in general, CR should be as 
Table 3. Strategy and parameters used for DE.

\begin{tabular}{ll}
\hline Strategy & DE/1/best/bin \\
Population size (NP) & 100 \\
Scaling factor (F) & 0.8 \\
Crossover constant (CR) & 1.0 \\
\hline
\end{tabular}

large as possible [22]. More details of basic version of DE (pseudo code), its strategies, and choosing of operating parameters were reported by Babu and Angira [23,24] and Babu and Munawar [22]. In this optimization, the strategies and parameters used for DE are presented in Table 3.

\subsection{Optimization problem formulation}

In this work, the goal of optimization is to find out the operating conditions, containing feed temperature, pressure, $\mathrm{HCl} / \mathrm{C}_{2} \mathrm{H}_{4}$ and $\mathrm{O}_{2} / \mathrm{C}_{2} \mathrm{H}_{4}$ molar ratios, and cooling medium temperature, that lead to the best performance of the reactor, i.e. objective function. For the best performance, four sub-functions are defined as follows:

- The first term: Maximize the ethylene conversion;

- The second term: Maximize the $\mathrm{HCl}$ conversion;

- The third term: Minimize the feed temperature. The main reason to develop this term is energy saving, reducing the size of the pre-heater, and also obtaining the highest conversion at the lowest possible temperature;

- The fourth term: Build up a logical relation between input flow rate and bed height; the residence time must be nearly 25 seconds.

Therefore, a suitable objective function is:

$$
J=\left|X_{\mathrm{C}_{2} \mathrm{H}_{4}}-1\right|+\left|X_{\mathrm{HC} \mathrm{L}}-1\right|-\left(\frac{1}{T_{f}}\right)+|\tau-25| .
$$

In the commercial ethylene oxychlorination reactors, the reaction occurs at a temperature range of 473$573 \mathrm{~K}[1,2]$. Therefore, the reactor temperature must not exceed $573 \mathrm{~K}$. However, local hot spots may still remain, creating some problems. For example, copper chloride $\left(\mathrm{CuCl}_{2}\right)$ as a catalyst can be evaporated above $673 \mathrm{~K}$, and it has been reported that the product distribution can change from high yields of 1,2-dichloroethane to a mixture of more highly chlorinated hydrocarbons such as 1,1,2-trichloroethane, trichloroethylene, vinyl chloride, and 1,2-dichloroethylene with increasing temperature $[1,20]$. Therefore, one constraint is considered as follows:

$$
473<T<573 \mathrm{~K} .
$$

The optimization problem considered above is then reformulated so as to include the constraints.
Penalty function method is employed for handling constraints. Inequality constraint, Eq. (13), is incorporated into Eq. (12) using penalty function. This method involves penalizing the objective function in proportion to the extent of constraint violation (i.e., the penalty function takes a finite value when a constraint is violated and a value of zero when constraint is satisfied). In the present case, we used $10^{7}$ as our penalty parameter, but this value depends on the order of magnitude of the variables in the problem; it may change from problem to problem.

Thus, the objective function considered for minimization, finally, is:

\section{Minimize}

$$
\mathrm{OF}=J+10^{7} \sum_{i=1}^{2} G_{i}^{2},
$$

where:

$$
\begin{aligned}
& G_{1}=\max \{0,(473-T)\}, \\
& G_{2}=\max \{0,(T-573)\} .
\end{aligned}
$$

The postulated optimization problem is solved with DE.

\section{Results and discussion}

\subsection{Base case}

In order to establish a reference point, simulation is carried out for a "base case". The reactor design data as well as operating conditions for the base case are given in Table 4 . The parametric sensitivity analysis is carried out to assess the impact of the variation of the following parameters on $\mathrm{C}_{2} \mathrm{H}_{4}$ and $\mathrm{HCl}$ conversions: height at minimum fluidization; feed temperature; pressure; cooling medium temperature; residence time; $\mathrm{HCl} / \mathrm{C}_{2} \mathrm{H}_{4}$ and $\mathrm{HCl} / \mathrm{O}_{2}$ molar ratios.

\subsection{Model validation}

The fluidized-bed model of ethylene oxychlorination is validated against the pilot plant data, reported by Cavaterra [25], for pilot plant working in Italy under the design specifications and input data listed in Table 4. It is observed in Table 5 that the model performed satisfactorily well under special case of industrial conditions, and simulation data are in good agreement with the observed plant data.

\subsection{Effect of residence time and bed height at minimum fluidization}

Figure 1(a) and (b) show the effect of residence time and bed height at minimum fluidization on $\mathrm{C}_{2} \mathrm{H}_{4}$ and $\mathrm{HCl}$ conversions, respectively. As the residence time increases, the superficial velocity and the bubble size decrease. When the bubble diameter decreases, the overall mass transfer area per unit bubble volume 
Table 4. Design and operating conditions of pilot plant.

\begin{tabular}{ll}
\hline \multicolumn{1}{c}{ Parameter } & Value \\
\hline Bed height at minimum fluidization & $7.0 \mathrm{~m}$ \\
Bed diameter & $3.4 \mathrm{~m}$ \\
Density of solid particles & $3075 \mathrm{~kg} / \mathrm{m}^{3}$ \\
Catalyst particle diameter & $80 \mu \mathrm{m}$ \\
Bed pressure & $400 \mathrm{kPa}$ \\
Feed temperature & $460 \mathrm{~K}$ \\
Cooling medium temperature & $360 \mathrm{~K}$ \\
Molar flow rate of $\mathrm{HCl} / \mathrm{C}_{2} \mathrm{H}_{4} / \mathrm{O}_{2}$ & $64 / 31.85 / 21.5 \mathrm{~mol} / \mathrm{s}$ \\
Residence time & $25 \mathrm{~s}$ \\
\hline
\end{tabular}

Table 5. Comparison between model predictions and pilot plant data at the base case.

\begin{tabular}{lccc}
\hline & Plant & Model & RE (\%) \\
\hline Outlet temperature (K) & 498 & 497.79 & 0.04 \\
$\mathbf{C}_{2} \mathbf{H}_{4}$ conversion (\%) & 99.3 & 99.55 & 0.25 \\
$\mathbf{H C l}$ conversion (\%) & 98.3 & 98.80 & 0.50 \\
\hline
\end{tabular}

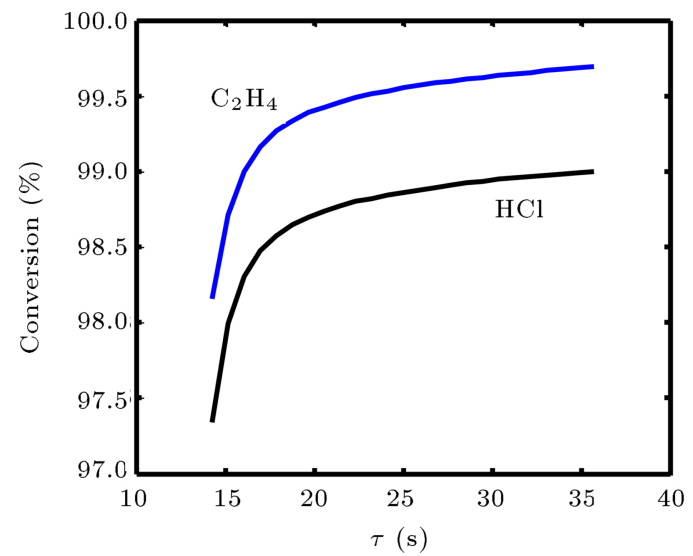

(a)

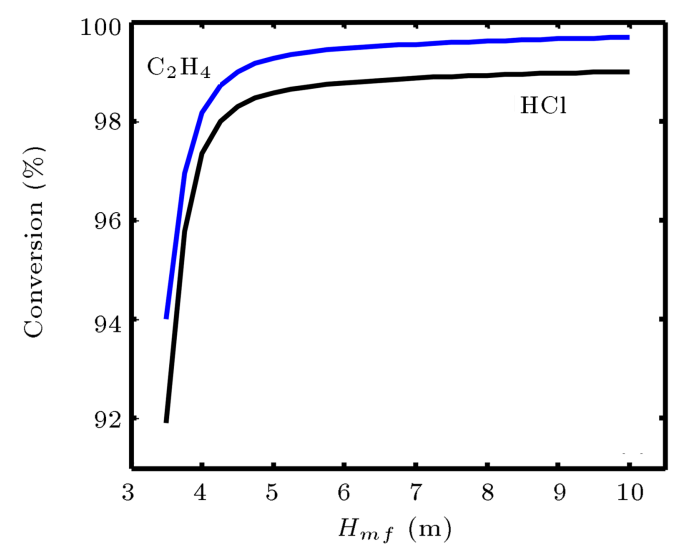

(b)

Figure 1. Effect of (a) residence time and (b) bed height at minimum fluidization on $\mathrm{C}_{2} \mathrm{H}_{4}$ and $\mathrm{HCl}$ conversions.

between bubble and dense phase increases; consequently, $\mathrm{C}_{2} \mathrm{H}_{4}$ and $\mathrm{HCl}$ conversions increase. It is very important to take care of the bubble diameter by selecting an appropriate reactant distributor in order to generate small bubbles. Furthermore, the reactor must be operated at sufficiently low superficial gas velocity. It is clear from Figure 1 (a) that $\mathrm{C}_{2} \mathrm{H}_{4}$ and $\mathrm{HCl}$ conversions increase asymptotically until they reach a residence time of $20 \mathrm{~s}$ with $\mathrm{C}_{2} \mathrm{H}_{4}$ and $\mathrm{HCl}$ conversions of $99.4 \%$ and $98.6 \%$, respectively; subsequently, the conversions increase slowly till the residence time of $35 \mathrm{~s}$. At residence times in excess of $35 \mathrm{~s}$, the conversions approach an equilibrium conversion. Therefore, $|\tau-25|$ is considered as a sub-function in the objective function.

In Figure 1(b), increasing the bed height at minimum fluidization increases $\mathrm{C}_{2} \mathrm{H}_{4}$ and $\mathrm{HCl}$ conversions, because an increase in bed height at a constant superficial velocity leads to an increase in residence time. This figure shows that small change of height at minimum fluidization, less than $5 \mathrm{~m}$, has significant effect on $\mathrm{C}_{2} \mathrm{H}_{4}$ and $\mathrm{HCl}$ conversions, but increasing the bed height at minimum fluidization means increasing the amount of catalyst.

\subsection{Effect of reactor pressure}

The effects of total pressure on $\mathrm{C}_{2} \mathrm{H}_{4}$ and $\mathrm{HCl}$ conversions are illustrated in Figure 2. Increasing the reactor pressure from 250 to $500 \mathrm{kPa}$ leads to an increase of $\mathrm{C}_{2} \mathrm{H}_{4}$ and $\mathrm{HCl}$ conversions from $96.9 \%$ to $99.8 \%$ and from $96.2 \%$ to $99.2 \%$, respectively. As shown in this figure, increase of pressure above $400 \mathrm{kPa}$ has slight effect on $\mathrm{C}_{2} \mathrm{H}_{4}$ and $\mathrm{HCl}$ conversions. Increasing the reactor pressure results in increasing the rate of reaction, and consequently, increasing $\mathrm{C}_{2} \mathrm{H}_{4}$ and $\mathrm{HCl}$ conversions. 


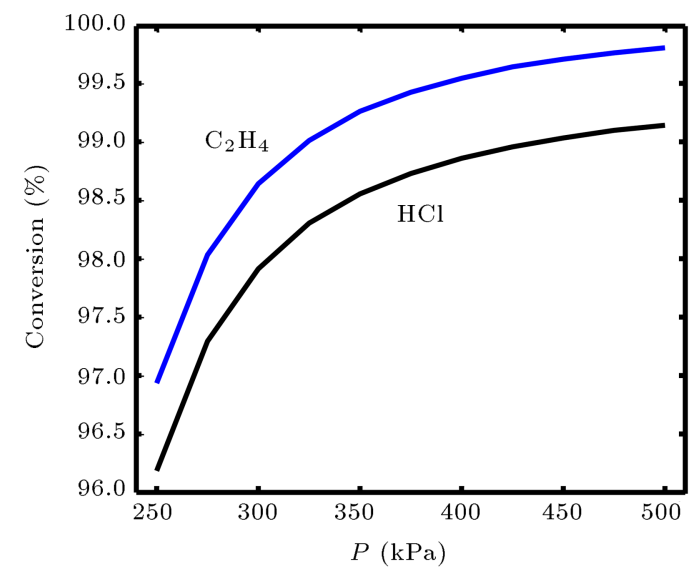

Figure 2. Effect of total pressure on $\mathrm{C}_{2} \mathrm{H}_{4}$ and $\mathrm{HCl}$ conversions.

\subsection{Effect of feed temperature}

Figure 3(a) and (b), respectively, show the influence of variation of feed temperature on $\mathrm{C}_{2} \mathrm{H}_{4}$ conversion and bed temperature. It is clear from this figure that when the feed temperature increases from 360 to 440 $\mathrm{K}$, the bed temperature increases from 377 to $498 \mathrm{~K}$ while $\mathrm{C}_{2} \mathrm{H}_{4}$ conversion increases from 0.09 to 0.99 as the rate of reaction increases. Also, the diffusivity of each component in the gas mixture increases as the feed temperature increases. Furthermore, the diffusivity of gas component affects the mass transfer coefficient. The variation of feed temperature above $440 \mathrm{~K}$ has very little effect on bed temperature and conversion. The feed temperature is selected as a decision variable for optimization, because the feed temperature has large effect on conversions.

\subsection{Effect of cooling medium temperature}

The effect of cooling medium temperature on $\mathrm{C}_{2} \mathrm{H}_{4}$ and $\mathrm{HCl}$ conversions and bed temperature is shown in Figure 4(a) and (b), respectively. When the cooling medium temperature increases from 360 to $440 \mathrm{~K}$, $\mathrm{C}_{2} \mathrm{H}_{4}$ and $\mathrm{HCl}$ conversions and bed temperature increase $0.47 \%, 0.55 \%$, and $14.5 \%$, respectively. Therefore, the variation of cooling medium temperature

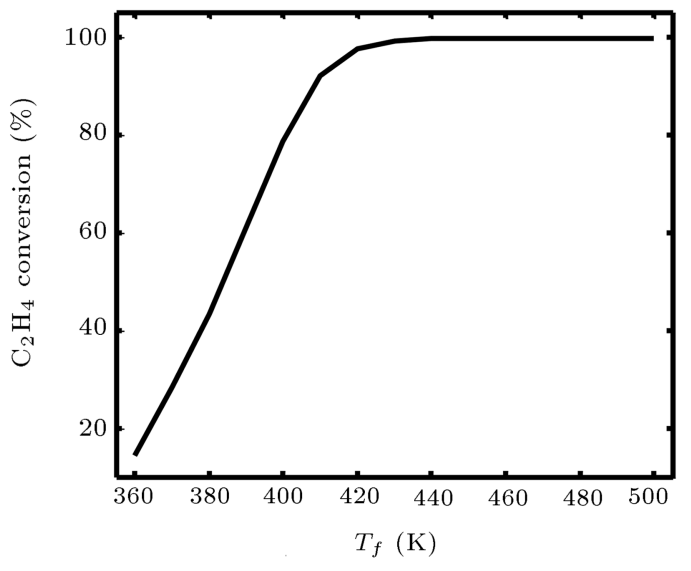

(a)

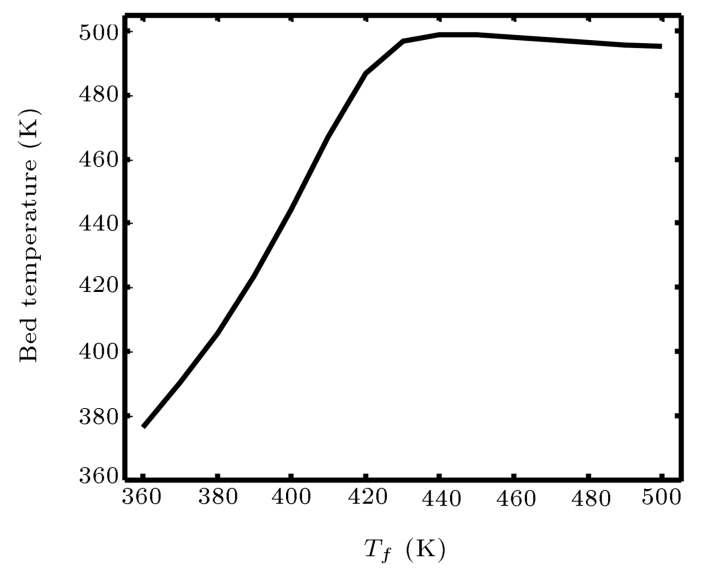

(b)

Figure 3. Effect of feed temperature on (a) ethylene conversion and (b) bed temperature.

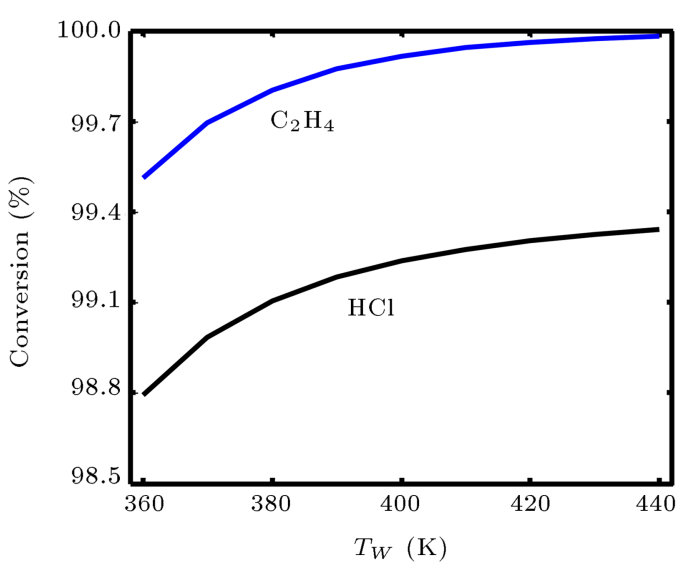

(a)

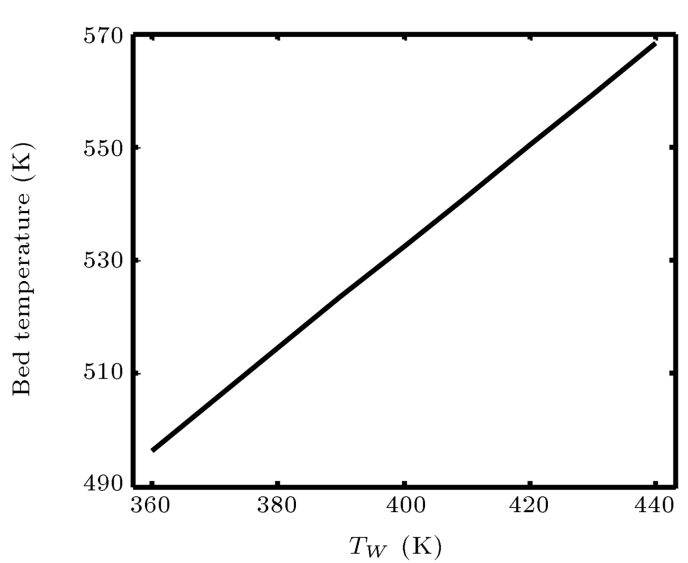

(b)

Figure 4. Effect of cooling medium temperature on (a) $\mathrm{C}_{2} \mathrm{H}_{4}$ and $\mathrm{HCl}$ conversions and (b) bed temperature. 
Table 6. Minimal and maximal values as well as optimal values of decision variables.

\begin{tabular}{lcccc}
\hline Optimization variables & Minimal values & Maximal values & $\mathbf{\pm} \boldsymbol{\alpha} \%$ & Optimal values \\
\hline$T_{f}(\mathrm{~K})$ & 400 & 510 & $\pm 12 \%$ & 440 \\
$T_{w}(\mathrm{~K})$ & 300 & 360 & - & 360 \\
$P(\mathrm{kPa})$ & 200 & 600 & $\pm 50 \%$ & 367.6 \\
$\mathrm{HCl}$ molar flow rate $(\mathrm{mol} / \mathrm{s})$ & 40 & 80 & $\pm 30 \%$ & 63.57 \\
$\mathrm{O}_{2}$ molar flow rate $(\mathrm{mol} / \mathrm{s})$ & 5 & 35 & $\pm 75 \%$ & 17.42 \\
\hline
\end{tabular}

has little effect on the conversions, but large effect on the bed temperature. An increase in cooling medium temperature will decrease the heat transfer rate and increase the bed temperature. The cooling medium temperature must be maintained below $440 \mathrm{~K}$ in order for the temperature of fluidized-bed ethylene oxychlorination reactor not to exceed $573 \mathrm{~K}$. This, in turn, prevents catalyst deactivation. Therefore, the cooling medium temperature plays an important role in this fluidized-bed reactor.

\subsection{Effect of feed molar ratio}

Figure 5 illustrates the variation of ethylene conversion versus $\mathrm{HCl} / \mathrm{C}_{2} \mathrm{H}_{4}$ and $\mathrm{HCl} / \mathrm{O}_{2}$ molar ratios at constant $\mathrm{HCl}$ molar flow rate, $64 \mathrm{~mol} / \mathrm{s}$. Decreasing $\mathrm{HCl} / \mathrm{C}_{2} \mathrm{H}_{4}$ molar ratio from 4 to 2 at constant $\mathrm{HCl} / \mathrm{O}_{2}$ molar ratio and increasing $\mathrm{HCl} / \mathrm{O}_{2}$ molar ratio from 2 to 4 at constant $\mathrm{HCl} / \mathrm{C}_{2} \mathrm{H}_{4}$ molar ratio result in increasing $\mathrm{C}_{2} \mathrm{H}_{4}$ conversion. Totally, when the feed molar ratio shifts to the stoicheiometry coefficient of ethylene oxychlorination reaction, the ethylene conversion will increase. It is clear from Figure 5 that at $\mathrm{HCl} / \mathrm{C}_{2} \mathrm{H}_{4}$ $=2, \mathrm{C}_{2} \mathrm{H}_{4}$ conversion at $\mathrm{HCl} / \mathrm{O}_{2}=3.5$ is higher than that at $\mathrm{HCl} / \mathrm{O}_{2}=4$. This is due to ethylene as the limiting reactant and the excess availability of oxygen.

\subsection{Results of the optimization with DE}

With due attention to parametric sensitivity analysis carried out in Sections 4.3-4.7, feed temperature, pressure, $\mathrm{HCl}$ and $\mathrm{O}_{2}$ molar flow rates, and cooling medium temperature are selected as optimization decision vari-

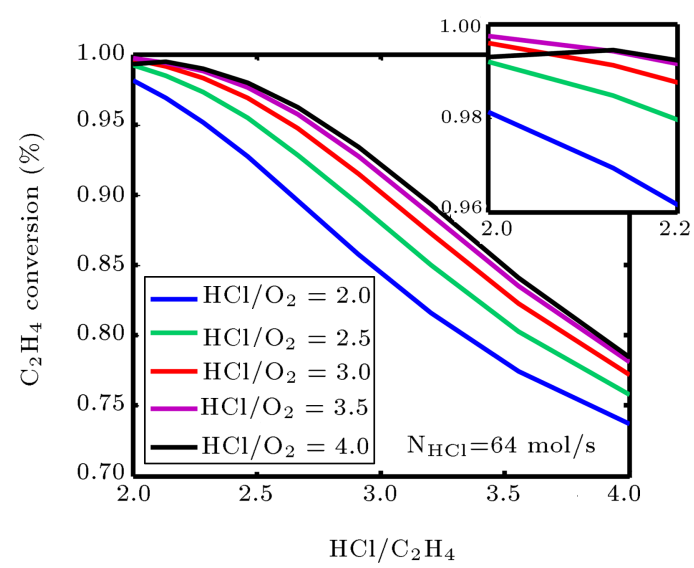

Figure 5. Effect of $\mathrm{HCl} / \mathrm{C}_{2} \mathrm{H}_{4}$ and $\mathrm{HCl} / \mathrm{O}_{2}$ molar ratio on ethylene conversion. ables to minimize the objective function (Eq. (14)). $\mathrm{C}_{2} \mathrm{H}_{4}$ molar flow rate is considered equal to $\mathrm{C}_{2} \mathrm{H}_{4}$ molar flow rate of pilot plant working in Italy $(31.85 \mathrm{~mol} / \mathrm{s})$, so that the results with the pilot plant data can be compared; it is not selected as a decision variable.

Minimal and maximal values of the decision variables are set, as shown in Table 6. The minimal and maximal allowed values of the decision variables were determined empirically based on reactor feed conditions, "base case", presented in Table 4. As shown in Table 6, the minimal and maximal values of most decision variables are disturbed $\pm \alpha \%$ around "base case". To ensure that the cooling water is in the liquid phase, the upper bound of cooling medium temperature is set at $360 \mathrm{~K}$.

In order to optimize the reactor, the $\mathrm{DE}$ code is coupled with the non-linear mathematical model (Eqs. (2)-(10)). Figure 6(a)-(e) show variations of objective function in terms of (a) $\mathrm{O}_{2}$ molar flow rate, (b) $\mathrm{HCl}$ molar flow rate, (c) pressure, (d) feed temperature, and (e) cooling medium temperature, respectively. As shown in these figures, the objective function is minimized in one point. These points, tabulated in

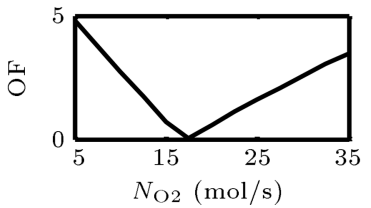

(a)

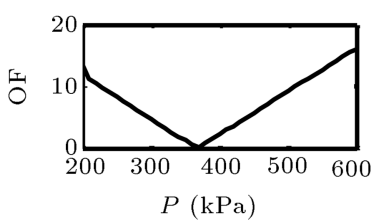

(c)

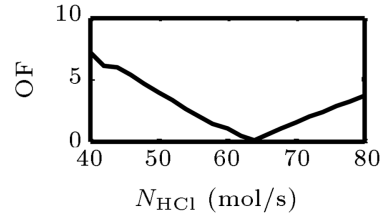

(b)

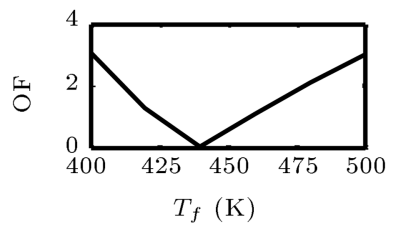

(d)

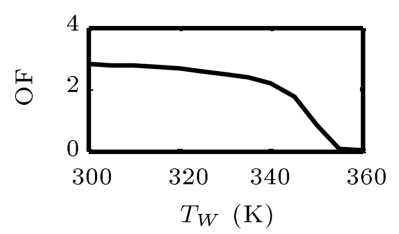

(e)

Figure 6. Variations of objective function versus $(\mathrm{a}) \mathrm{O}_{2}$ molar flow rate, (b) $\mathrm{HCl}$ molar flow rate, (c) pressure, (d) feed temperature, and (e) cooling medium temperature. 
the last column of Table 6, are optimal operating conditions of the ethylene oxychlorination reactor. Under these conditions, $\mathrm{HCl} / \mathrm{C}_{2} \mathrm{H}_{4}$ and $\mathrm{O}_{2} / \mathrm{C}_{2} \mathrm{H}_{4}$ molar ratios are 2 and 0.55 , respectively, which are in very good agreement with the stoichiometric coefficient of ethylene oxychlorination reaction (Eq. (1)). Residence time $25 \mathrm{~s}$, bed temperature $510.2 \mathrm{~K}, \mathrm{HCl}$ and $\mathrm{C}_{2} \mathrm{H}_{4}$ conversions $99.5 \%$ and $99.7 \%$, respectively, are associated with the set of optimal operating conditions presented in Table 6 . The results obtained, according to optimization, show an increase of $1.1 \%$ in the $\mathrm{HCl}$ conversion and a decrease of $8.1 \%$ and $18 \%$ in the pressure and $\mathrm{O}_{2} / \mathrm{C}_{2} \mathrm{H}_{4}$ molar ratio, respectively. Also, decreasing feed temperature from 460 to $440 \mathrm{~K}$ leads to saving energy and reducing the size of the pre-heater.

\section{Conclusion}

Optimization of fluidized-bed ethylene oxychlorination reactor is studied by a steady-state mathematical model based on the two-phase theory of fluidization. A base case is generated considering similar operating conditions to pilot plant working in Italy. The model is validated against this pilot plant data, and good agreement is obtained. The effects of different operating variables on $\mathrm{C}_{2} \mathrm{H}_{4}$ and $\mathrm{HCl}$ conversions are numerically investigated. DE is used as a powerful optimization technique to determine the optimal reactor operating conditions. The feed temperature, pressure, $\mathrm{HCl} / \mathrm{C}_{2} \mathrm{H}_{4}$ and $\mathrm{O}_{2} / \mathrm{C}_{2} \mathrm{H}_{4}$ molar ratios, and cooling medium temperature are selected as decision variables to minimize the objective function. The results show that the obtained optimal operating conditions can increase $\mathrm{HCl}$ conversion by $1.1 \%$ as well as a decrease of $8.1 \%$ and $18 \%$ in the pressure and $\mathrm{O}_{2} / \mathrm{C}_{2} \mathrm{H}_{4}$ molar ratio, respectively. Also, a decrease of $20^{\circ} \mathrm{C}$ is observed in the optimal feed temperature which results in energy saving. Also, the following key results are achieved:

- Increasing the height at minimum fluidization more than $5 \mathrm{~m}$ has no significant effect on $\mathrm{C}_{2} \mathrm{H}_{4}$ and $\mathrm{HCl}$ conversions. Therefore, above $5 \mathrm{~m}$ height, there is no economic justification for the extra capital investments on reactor volume and catalyst quantity;

- The residence time must be more than $20 \mathrm{~s}$ to achieve high conversion. This might occur by choosing a proper reactant distributor and regulating the superficial gas velocity;

- Increasing pressure and feed temperature above 400 $\mathrm{kPa}$ and $440 \mathrm{~K}$, respectively, will have no significant effect on the conversion. An increase in temperature (above $440 \mathrm{~K}$ ) causes loss of energy and enlargement of the size of the preheater;

- The cooling medium temperature should be less than $440 \mathrm{~K}$ to avoid catalyst deactivation;
- The optimum ethylene and $\mathrm{HCl}$ conversions (i.e., 99.5 and $99.7 \%$ ) can be achieved by working at $\mathrm{HCl} / \mathrm{C}_{2} \mathrm{H}_{4}$ and $\mathrm{O}_{2} / \mathrm{C}_{2} \mathrm{H}_{4}$ molar ratios of 2 and 0.55 , feed and cooling medium temperatures of 440 and $360 \mathrm{~K}$, respectively, and pressure $367.6 \mathrm{kPa}$.

\section{Nomenclature}

A Cross-sectional area of bed $\left(\mathrm{m}^{2}\right)$

$A_{b} \quad$ Cross-sectional area of bubble phase $\left(\mathrm{m}^{2}\right)$

$A_{w} \quad$ Area of heat transfer between coolant and bed (m2)

$C_{p g} \quad$ Gas heat capacity (J/kg K)

$D \quad$ Bed diameter (m)

$D_{i j} \quad$ Diffusivity of component $i$ in component $j\left(\mathrm{~m}^{2} / \mathrm{s}\right)$

$D_{i m} \quad$ Diffusivity of component $i$ in gas mixture $\left(\mathrm{m}^{2} / \mathrm{s}\right)$

$d_{B} \quad$ Bubble diameter $(\mathrm{m})$

$d_{p} \quad$ Particle diameter $(\mathrm{m})$

$g \quad$ Gravitational acceleration $\left(\mathrm{m} / \mathrm{s}^{2}\right)$

$H \quad$ Bed height $(\mathrm{m})$

$\left(H_{b d}\right)_{b} \quad$ Inter-phase heat transfer coefficient between bubble and dense phases based on bubble volume $\left(\mathrm{J} / \mathrm{m}^{3} \mathrm{~s} \mathrm{~K}\right)$

$\left(H_{b c}\right)_{b} \quad$ Inter-phase heat transfer coefficient between bubble and cloud phases based on bubble volume $\left(\mathrm{J} / \mathrm{m}^{3} \mathrm{~s} \mathrm{~K}\right)$

$\left(H_{c d}\right)_{b} \quad$ Inter-phase heat transfer coefficient between cloud and dense phases based on bubble volume $\left(\mathrm{J} / \mathrm{m}^{3} \mathrm{~s} \mathrm{~K}\right)$

$h_{w} \quad$ Bed to cooling surface heat transfer coefficient $\left(\mathrm{J} / \mathrm{m}^{2} \mathrm{~s} \mathrm{~K}\right)$

$\left(K_{b d}\right)_{i b} \quad$ Inter-phase mass transfer coefficient between bubble and dense phases based on bubble volume $(1 / \mathrm{s})$

$\left(K_{b c}\right)_{i b} \quad$ Interphase mass transfer coefficient between bubble and cloud phases based on bubble volume $(1 / \mathrm{s})$

$\left(K_{c d}\right)_{i b} \quad$ Interphase mass transfer coefficient between cloud and dense phases based on bubble volume $(1 / \mathrm{s})$

$k_{g} \quad$ Thermal conductivity of gas $(\mathrm{J} / \mathrm{K} \mathrm{m} \mathrm{s})$

$M \quad$ Molecular weight

$N \quad$ Molar flow rate $(\mathrm{mol} / \mathrm{s})$

OF Objective Function

$P \quad$ Reactor pressure $(\mathrm{Pa})$

$Q \quad$ Volumetric flow rate $\left(\mathrm{m}^{3} / \mathrm{s}\right)$ 
$R \quad$ Gas constant $\left(\mathrm{m}^{3} \mathrm{~Pa} / \mathrm{g} \mathrm{mol} \mathrm{K}\right)$

$r \quad$ Kinetic rate of reaction $\left(\mathrm{kg} \mathrm{mol} / \mathrm{m}^{3} \mathrm{~s}\right)$

$T \quad$ Temperature (K)

$u \quad$ Superficial gas velocity $(\mathrm{m} / \mathrm{s})$

$V \quad$ Volume of overall reactor $\left(\mathrm{m}^{3}\right)$

$x \quad$ Mole fraction

$z \quad$ Distance along bed height $(\mathrm{m})$

\section{Greek letters}

$\gamma_{i} \quad$ Stoichiometric coefficient of component $i$ in reaction

$\delta \quad$ Fraction of bed consisting of bubbles

$\Delta H_{i} \quad$ Heat of reaction $(\mathrm{J} / \mathrm{kg} \mathrm{mol})$

$\varepsilon \quad$ Bed void fraction

$\mu \quad$ Viscosity $(\mathrm{kg} / \mathrm{m} \mathrm{s})$

$\rho_{g} \quad$ Density of gas $\left(\mathrm{kg} / \mathrm{m}^{3}\right)$

$\rho_{p} \quad$ Density of solid particles $\left(\mathrm{kg} / \mathrm{m}^{3}\right)$

$\tau \quad$ Residence time (s)

$\varphi_{s} \quad$ Sphericity of particles

\section{Subscripts}

Bubble phase gas

$d \quad$ Dense phase gas

df $\quad$ Inlet of dense phase gas

$f \quad$ Fresh feed gas

$i \quad i$ th component

$m f \quad$ Minimum fluidization

$w \quad$ Cooling medium

\section{References}

1. Magistro, A.J. and Cowfer, J.A. "Oxychlorination of ethylene", J. Chem. Educ., 63, pp. 1056-1058 (1986).

2. Naworski, J.S. and Velez, E.S. "Oxychlorination of ethylene”, Appl. Ind. Catal., 1, p. 239 (1983).

3. Al-Zahrani, S.M., Aljodai, A.M. and Wagialla, K.M. "Modeling and simulation of 1,2-dichloroethane production by ethylene oxychlorination in fluidized-bed reactor", Chem. Eng. Sci., 56, pp. 621-626 (2001).

4. Prasad, P.S.S., Prasad, K.B.S. and Ananth, M.S. "Parameter estimation in a fixed-bed reactor operating under unsteady state: Oxychlorination of ethylene", Ind. Eng. Chem. Res., 40, pp. 5487-5495 (2001).

5. Go, K.S., Kim, Y., Son, S.R. and Kim, S.D. "1,2dichloroethane production by two-step oxychlorination reactions in a fluidized bed reactor", Chem. Eng. Sci., 65, pp. 499-503 (2010).

6. Keshavarz Moraveji, M., Davarnejad, R., Filsoof, A. and Asgari, M. "Reactor modeling of ethylene oxychlorination for 1,2-dichloroethane production", World Applied Sciences Journal, 21(8), pp. 1113-1115 (2013).
7. Montebelli, A., Tronconi, E., Orsenigo, C. and Ballarini, N. "Kinetic and modeling study of the ethylene oxychlorination to 1,2-dichloroethane in fluidized-bed reactors", Ind. Eng. Chem. Res., 54, pp. 9513-9524 (2015).

8. Kunii, D. and Levenspiel, O., Fluidization Engineering, Wiley, New York (1991).

9. Toor, F.D. and Calderbank, P.H. Proceedings of the Tripartite Chemical Engineering Conference, London Inst. of Chemical Engrs., Montreal, Quebec (1968).

10. Fryer, C. and Potter, O.E. "Bubble size variation in two-phase models of fluidized bed reactors", Powder Technology, 6, pp. 317-322 (1972).

11. Wgialla, K.M., Helal, A.M. and Elnashaie, S.S.E.H. "The use of mathematical and computer models to explore the applicability of fluidized bed technology for highly exothermic catalytic reactions. I. Oxidative dehydrogenation of butane", Math. Comput. Modeling, 15, pp. 17-31 (1991).

12. Broadhurst, T.E. and Becker, H.A. "Onset of fluidization in slugging beds of uniform particles", AIChEJ, 21, pp. 238-247 (1975).

13. Mori, S. and Wen, C.Y. "Estimation of bubble diameter in gaseous fluidized beds", AIChEJ, 21, pp. 109-115 (1975).

14. Davidson, J.F. and Harrison, D. Fluidized Particles, Cambridge University Press, New York (1963).

15. Renz, U., von Wedel, G. and Reinartz, A. "Heat transfer characteristics of the FBC at Acchen Technical University", Proceedings of the 1987 International Conference on Fluidized Bed Combustion, American Society of Mechanical Engineers, New York (1987).

16. Fuller, E.N., Schettler, P.D. and Giddings, J.C. "A new method for prediction of binary gas phase diffusion coefficients", Ind. Eng. Chem., 58, pp. 19-27 (1966).

17. Reid, R.C., Prausnitz, J.M. and Sherwood, T.K., Properties of Gases and Liquids, McGraw-Hill, New York (1966).

18. Carrubba, R.V. and Spencer, J.L. "Kinetics of the oxychlorination of ethylene", Ind. Eng. Chem. Process Des. Develop., 9, pp. 414-419 (1970).

19. Fengqiu, C., Yongrong, Y., Shunni, R. and Gatang, C. "Studies on ethylene oxychlorination, II. Reaction mechanism and kinetics", Petrochemical Technology, 23, pp. 421-425 (1994).

20. Wachi, W. and Asai, Y. "Kinetics of 1,2 dichloroethane formation from ethylene and cupric chloride", Ind. Eng. Chem. Res., 33, pp. 259-264 (1994).

21. Price, K. and Storn, R. "Differential Evolution (DE) for continuous function optimization", Homepage of differential evolution as on http://www.ICSI.Berkeley.edu/wstorn/code.html (May 2006). 
22. Babu, B.V. and Munawar, S.A. "Differential evolution strategies for optimal design of shell-and-tube heat exchangers", Chem. Eng. Sci., 62, pp. 3720-3739 (2007).

23. Babu, B.V. and Angira, R. "Modified differential evolution (MDE) for optimization of non-linear chemical processes", Comput. Chem. Eng., 30, pp. 989-1002 (2006).

24. Angira, R. and Babu, B.V. "Optimization of process synthesis and design problems: A modified differential evolution approach", Chem. Eng. Sci., 61, pp. 47074721 (2006).

25. Cavaterra, E. "Catalysts to make dichloroethane", Hydrocarbon Processing, 67, pp. 63-67 (1988).

\section{Biographies}

Mohammad Hasan Khademi is an Associate Professor of Chemical Engineering at Isfahan University, Isfahan, Iran. His main research interests include process modeling, simulation and optimization, especially, in the field of chemical reactor.

Sajjad Angooraj Taghavi obtained his BS degree in Chemical Engineering in 2006 from Islamic Azad University of Gachsaran, Iran, and his MS degree in 2013 from the Department of Chemical Engineering at Fars Science and Research Branch, Islamic Azad University, Shiraz, Iran. His main research interests include modeling and optimization of chemical reactors. 